\title{
Débridement-valvotomy for aortic stenosis in adults
}

\author{
A follow-up of 76 patients \\ P. J . HURLEY ${ }^{1}$, J . B. LOWE, AND B. G B ARRATT-BOYES \\ From the Cardiothoracic Surgical Unit, Green Lane Hospital, Auckland, New Zealand
}

\begin{abstract}
Seventy-six adults who had débridement-valvotomy for severe aortic stenosis are reviewed. Of these, 61 had isolated aortic valve stenosis and 15 had multivalvar disease. Twenty-six patients $(34 \%)$ died at or subsequent to surgery. Thirty-eight of the 40 survivors with isolated aortic valve disease have been followed up for between 21 and 70 (mean 46) months after surgery, and detailed evidence as to the state of the aortic valve was obtained in 34 of these either by left heart catheterization or at operation. Only one result was completely acceptable. The great majority of patients were found to have redeveloped important aortic stenosis, and in many this was already sufficiently severe to warrant further surgery. The initial degree of valve calcification seemed to have little bearing on the final result except in the multivalve group. Other series are reviewed. The operation has become increasingly unpopular, but reports continue to suggest that it may still have a place. Our results suggest that the procedure should be discarded.
\end{abstract}

Débridement-valvotomy, or sculpturing, of the aortic valve for calcific aortic stenosis was widely practised five to six years ago but has now largely been superseded by techniques involving valve replacement. In view of the disfavour into which this operation is falling, it is important to assess carefully late results in order to decide whether the procedure still deserves a place in modern cardiac surgery.

Our experience covers 76 adults with aortic stenosis operated on between 1959 and early 1964 and followed up in all but two instances. Children have not been considered (since the paediatric group raises questions outside the scope of this review), nor has aetiology, but patients with multivalvar disease are considered separately from those with involvement of the aortic valve alone.

\section{SINGLE VALVE GROUP (AORTIC VALVE ONLY AFFECTED)}

This comprised 61 patients, 47 men and 14 women. Their ages at the time of operation are listed in Table I. The youngest was 19 and the

'Present address : Medical Unit. Auckland Hospital, Auckland, oldest 71 years. Three patients had had a previous blind aortic valvotomy.

On clinical grounds, all patients were considered to have severe valve stenosis without more than trivial regurgitation. All had cardiac symptoms, and the large majority were at least moderately incapacitated. Fifty-eight had dyspnoea on effort, mild in 13 but moderate or severe in the remainder. Twenty-two had had paroxysmal nocturnal dyspnoea, and 13 had a history of congestive heart failure. Forty-four patients had angina pectoris, and 33 had had at least one attack of effort syncope.

Every patient had a basal systolic ejection murmur, but in only 36 was this murmur of

T A B L E I

AGE INCIDENCE

\begin{tabular}{c|c} 
Age (years) & Total \\
\hline $10-19$ & 1 \\
$20-29$ & 2 \\
$30-39$ & 9 \\
$40-49$ & 8 \\
$50-59$ & 29 \\
$60-69$ & 11 \\
$70-79$ & 1 \\
\hline
\end{tabular}


greater than moderate intensity; in 39 a systolic thrill was present. In addition, 37 patients had an early diastolic murmur at the left sternal edge, but it was faint in all but two patients, neither of whom appeared to have significant aortic regurgitation at surgery. In 36 patients the second heart sound split paradoxically. Forty-seven patients had an anacrotic pulse. Only three were in congestive heart failure, but many were taking digitalis preparations.

The electrocardiogram showed sinus rhythm in 56 patients, atrial fibrillation in four, and complete heart block in one. All but three records, where there was complete bundle branch block, showed left ventricular hypertrophy as judged by voltage criteria. Twenty-eight had, in addition, marked $T$ wave inversion and $S T$ segment depression in left ventricular leads, and another 27 had flat or slightly inverted $\mathrm{T}$ waves in these leads.

The chest radiograph showed convincing cardiomegaly in 15 patients. On fluoroscopy, calcification of the aortic valve was not visible in five patients, appeared light in seven, moderate in 15 , and very heavy in 34 patients.

Since the diagnosis of severe aortic stenosis was generally made on clinical grounds, cardiac catheterization was considered necessary preoperatively in only seven instances.

OPERATIVE PROCEDURE AND FINDINGS The operations were performed between September 1959 and January 1964. Cardiopulmonary bypass was used in all cases, with direct vision of the aortic valve. The method of supporting the myocardium during the period of aortic cross-clamping varied. In three early cases, potassium arrest was used without apparent ill effect. In eight others, 300 to $500 \mathrm{ml}$. of cold oxygenated blood was perfused through the coronary arteries before the aorta was opened, using a needle in the ascending aorta proximal to the aortic clamp. In the remainder, continuous coronary artery perfusion was used, usually through the left coronary artery only, either at normothermia or mild hypothermia. After exposure, the aortic valve was decalcified piecemeal with the aid of forceps, scalpel, bone nibblers, and scissors, and the fused commissures were opened as far as was found practicable. The aim was to produce a mobile, competent, calciumfree valve.

Thirty-one valves were thought to be essentially bicuspid, and the remainder tricuspid, as far as could be ascertained in the presence of grossly distorted valve architecture in some cases. In one patient, the valve was almost free of calcium, and in five, calcification was minor. Of the remainder, 16 had moderately heavy, and 39 gross, calcification. In most instances the degrees of calcification and stenosis went hand in hand. Three valves appeared to be moderately incompetent and another seven slightly so; all the other valves appeared competent. Pressure gradients across the aortic valve before and after repair were measured in 45 patients, and the results are shown in Table II.

T A B L E I I

OPERATIVE DATA IN 45 PATIENTS

\begin{tabular}{|c|c|c|c|c|c|}
\hline & & & & \multicolumn{2}{|c|}{$\begin{array}{c}\text { Average Peak Systolic } \\
\text { Pressure (mm. Hg) }\end{array}$} \\
\hline & & & & $\begin{array}{c}\text { Before } \\
\text { Valvotomy }\end{array}$ & $\begin{array}{c}\text { After } \\
\text { Valvotomy }\end{array}$ \\
\hline $\begin{array}{l}\text { Left ventricle } \\
\text { Aorta }\end{array}$ & $\begin{array}{l}\cdots \\
\cdots\end{array}$ & $\begin{array}{l}\cdots \\
\cdots\end{array}$ & $\begin{array}{l}\cdots \\
\cdots\end{array}$ & $\begin{array}{l}161 \\
104 \\
\end{array}$ & $\begin{array}{r}114 \\
98\end{array}$ \\
\hline \multicolumn{4}{|c|}{$\begin{array}{c}\text { Average peak systolic gradient } \\
(\mathrm{mm} . \mathrm{Hg})\end{array}$} & 57 & 16 \\
\hline
\end{tabular}

The surgeon reported a technically good débridement-valvotomy in 40 patients, a fair result in 11 , and a poor one in ten. In six of the cases regarded as poor results, damage to thin, very friable valves necessitated replacement with Teflon leaflets (Bahnson, Spencer, Busse, and Davis, 1960).

\section{RESULTS}

MORTALITY (Tables III and IV) Each of the four patients with a technically poor operation who did not receive Teflon prostheses died on the operating table due to severe surgically produced aortic regurgitation. Another four patients had technically satisfactory débridements, but it was impossible to restart the heart. Two of the six patients who received Teflon prostheses also died in hospital, as did three others who had had standard débridements. Six more patients have subsequently died. Four of these had a very satisfactory débridement but necropsy in one showed a heavily calcified, grossly restenosed aortic valve. The other two late deaths occurred in patients with Teflon prostheses. Thus the total mortality for the single valve group (including those receiving Teflon cusps) was $31 \%$ (19 patients).

FOLLOW-UP STATUS OF SURVIVORS In addition to the two Teflon cusp survivors, who have been excluded from further analysis, 40 of the original 61 patients are still alive. One of these could not be 
T A B L E I I I

HOSPITAL MORTALITY

\begin{tabular}{|c|c|c|c|}
\hline Cause & & & No. \\
\hline 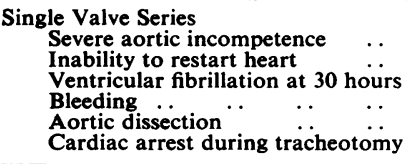 & $\begin{array}{l}\cdots \\
\cdots \\
\cdots \\
\cdots \\
\cdots\end{array}$ & $\begin{array}{l}\cdots \\
\cdots \\
\cdots \\
\cdots \\
\cdots\end{array}$ & $\begin{array}{l}4 \\
4 \\
1 \\
2 \\
1 \\
1\end{array}$ \\
\hline Total & $\ldots$ & .. & 13 \\
\hline $\begin{array}{l}\text { Multivalve Series } \\
\text { Severe aortic incompetence } \\
\text { Inability to restart heart }\end{array}$ & $\begin{array}{l}\cdots \\
\cdots\end{array}$ & $\begin{array}{l}\cdots \\
\cdots\end{array}$ & $\begin{array}{l}2 \\
1\end{array}$ \\
\hline Total & $\ldots$ & . & 3 \\
\hline
\end{tabular}

T A B L E I V

LATE MORTALITY (10 PATIENTS)

\begin{tabular}{|c|c|c|}
\hline $\begin{array}{c}\text { Age at } \\
\text { Operation }\end{array}$ & Cause of Death & $\begin{array}{l}\text { Post-operative } \\
\text { Interval (mths) }\end{array}$ \\
\hline \multicolumn{3}{|c|}{ Single Valve Series } \\
\hline $\begin{array}{l}57 \\
50 \\
49 \\
71 \\
64 \\
55\end{array}$ & $\begin{array}{l}\text { Congestive heart failure } \\
\text { (Tefion cusp) } \\
\text { Acute heart failure } \\
\text { Congestive heart failure } \\
\text { Sudden death (Teflon cusp) } \\
\text { Details unknown } \\
\text { Severe aortic restenosis; } \\
\text { myocardial infarction }\end{array}$ & $\begin{array}{r}7 \\
27 \\
28 \\
36 \\
36 \\
38\end{array}$ \\
\hline \multicolumn{3}{|c|}{ Multivalve Series } \\
\hline $\begin{array}{l}48 \\
49 \\
48 \\
34\end{array}$ & $\begin{array}{l}\text { Sudden death } \\
\text { Sudden death } \\
\text { Congestive heart failure } \\
\text { Details unknown }\end{array}$ & $\begin{array}{r}4 \\
36 \\
43 \\
54\end{array}$ \\
\hline
\end{tabular}

traced and another refused to attend for followup, but the remaining 38 were re-examined at post-operative intervals of from 21 to 70 months, with a mean of 46 months.

Following surgery, 36 of the 38 patients had felt an initial symptomatic improvement. At followup, 23 continued to feel better than they had felt pre-operatively, eight felt much the same, and seven felt worse. Sixteen still had angina pectoris, 32 had some dyspnoea, and six were subject to attacks of effort syncope.

Twenty-five patients now had an anacrotic pulse; 24 had a loud systolic murmur or thrill. In 13 the second heart sound split paradoxically, 16 patients had a gallop rhythm, and 22 an early diastolic murmur.

In the electrocardiogram, the degree of left ventricular hypertrophy was substantially unchanged in 25 patients, had lessened in five, and had increased in eight. Fifteen patients showed some degree of cardiomegaly in the chest radio $\frac{\vec{f}}{+}$ graph. Aortic valve calcification could be seen on? fluoroscopy in all but one patient. In 12 patients은 it appeared light, in 13 moderate, and in 12 heavy? This represented improvement in 14 instances, noळ change in 17, and deterioration in seven.

Of thèse 38 patients, 29 agreed to cardiaccatheterization. The results are shown in Table$\mathrm{V}$, in which patients are arranged in three groups $\vec{\omega}$ according to the severity of valve calcification at? the time of operation. In each group patients are arranged in ascending order of peak systolioi pressure gradient at catheterization. At the original operations, the valves in 18 of these $29 \dot{\omega}$ patients had been found to be grossly calcified, $\vec{\perp}$ eight had more moderate calcification, althougho in some of these also there was tight stenosis, andthree had only mild calcification. In 19 cases,, the surgeon had regarded the final result of débridement-valvotomy as good; in the remain- $\overrightarrow{0}$ der, the valve had been substantially improved, $>$ although some immobility or calcification of the cusps remained. The peak systolic gradient, as recorded across the valve at the end of surgery, must be interpreted with caution in view of theo patient's abnormal and variable haemodynamic state, but the average in the group classified as good was $12 \mathrm{~mm}$. $\mathrm{Hg}$, and in the fair group, $32 \mathrm{O}$ $\mathrm{mm}$. Hg. In contrast, at follow-up catheterization only four patients had peak systolic gradients across the aortic valve of less than $40 \mathrm{~mm}$. $\mathrm{Hg}$. One of these four, reviewed 47 months after operation, appeared to have had a good result by clinical and catheter assessment ; another had ${ }_{-}^{x}$ no residual gradient at 58 months but was the 3 . only patient of the entire 29 who had significanto aortic incompetence (demonstrated by cineangiography). In the other two, the follow-up intervals were shorter, namely 27 and 37 months. Most of the remainder had clear evidence of severe re- $-\frac{D}{0}$ stenosis of the aortic valve. The average peak systolic gradient across the valve for the whole N group of 29 was $74 \mathrm{~mm}$. $\mathrm{Hg}$; the maximum gradient was $155 \mathrm{~mm}$. $\mathrm{Hg}$.

Eight of these 29 patients have had further ${ }^{\infty}$ aortic valve surgery since catheterization, and all were found to have tight restenosis.

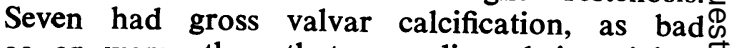
as or worse than that preceding their original ${ }_{T}^{+}$ débridement-valvotomy, and some valves looked as if no previous procedure had ever been per- $\frac{\vec{\Phi}}{\mathrm{D}}$ formed; yet, at the original operation, the $\frac{?}{\mathbb{D}}$ surgeon felt he had produced a completely satis- $\stackrel{\mathbb{Q}}{9}$ factory valve with good decalcification in six of the eight and reasonable results in the other two. All had homograft valve replacement at the 
T A B L E V

OPERATIVE AND FOLLOW-UP DATA

\begin{tabular}{|c|c|c|c|c|c|c|c|c|}
\hline \multirow[b]{2}{*}{ Age $^{1}$} & \multirow[b]{2}{*}{ Sex } & \multicolumn{4}{|c|}{ Data Obtained during Operation } & \multicolumn{3}{|c|}{ Follow-up Catheter Data } \\
\hline & & $\begin{array}{l}\text { Degree of } \\
\text { Calcification }\end{array}$ & $\begin{array}{l}\text { Degree of } \\
\text { Stenosis }\end{array}$ & $\begin{array}{c}\text { Peak Systolic } \\
\text { Gradient } \\
\text { (mm.Hg) after } \\
\text { Débridement }\end{array}$ & $\begin{array}{l}\text { Surgeon's } \\
\text { Assessment } \\
\text { of Result }\end{array}$ & $\begin{array}{c}\text { Peak Systolic } \\
\text { Gradient } \\
(\mathrm{mm} . \mathrm{Hg})\end{array}$ & $\begin{array}{c}\text { Cardiac Index } \\
\left(1 . / \mathrm{min} . / \mathrm{m}^{2}\right)\end{array}$ & $\begin{array}{c}\text { Time from } \\
\text { Surgery } \\
\text { (mths) }\end{array}$ \\
\hline
\end{tabular}

\begin{tabular}{|c|c|c|c|c|c|c|c|c|}
\hline \multicolumn{9}{|c|}{ Univalve Series } \\
\hline $\begin{array}{l}31 \\
59 \\
41\end{array}$ & $\begin{array}{l}\mathbf{F} \\
\mathbf{M} \\
\mathbf{M}\end{array}$ & $\begin{array}{l}+ \\
+ \\
+\end{array}$ & $\begin{array}{c}++ \\
+ \\
+++\end{array}$ & $\begin{array}{c}\text { NR } \\
4 \\
28\end{array}$ & $\begin{array}{l}\text { Good } \\
\text { Good } \\
\text { Good }\end{array}$ & $\begin{array}{l}\text { O(AR) } \\
34 \\
64\end{array}$ & $\begin{array}{l}2 \cdot 1 \\
2 \cdot 9 \\
3 \cdot 0\end{array}$ & $\begin{array}{l}58 \\
27 \\
63\end{array}$ \\
\hline $\begin{array}{l}53 \\
19 \\
39 \\
35 \\
53 \\
65 \\
52 \\
40\end{array}$ & $\begin{array}{l}\mathbf{M} \\
\mathbf{M} \\
\mathbf{M} \\
\mathbf{M} \\
\mathbf{M} \\
\mathbf{M} \\
\mathbf{M} \\
\mathbf{M}\end{array}$ & $\begin{array}{l}++ \\
++ \\
++ \\
++ \\
++ \\
++ \\
++ \\
++\end{array}$ & $\begin{array}{c}++ \\
+++ \\
+++ \\
+ \\
+ \\
+++ \\
+++ \\
+++\end{array}$ & $\begin{array}{c}4 \\
12 \\
0 \\
N R \\
18 \\
15 \\
16 \\
36\end{array}$ & $\begin{array}{l}\text { Good } \\
\text { Good } \\
\text { Good } \\
\text { Good } \\
\text { Good } \\
\text { Good } \\
\text { Fair } \\
\text { Fair }\end{array}$ & $\begin{array}{r}42 \\
44 \\
50 \\
64 \\
80 \\
104 \\
110 \\
155\end{array}$ & $\begin{array}{l}2 \cdot 4 \\
3 \cdot 1 \\
2 \cdot 9 \\
3 \cdot 9 \\
3 \cdot 2 \\
1 \cdot 9 \\
2 \cdot 8 \\
4 \cdot 0\end{array}$ & $\begin{array}{l}55 \\
70 \\
44 \\
47 \\
31 \\
56 \\
53 \\
50\end{array}$ \\
\hline $\begin{array}{l}35 \\
52 \\
51 \\
59 \\
54 \\
54 \\
34 \\
57 \\
42 \\
47 \\
60 \\
36 \\
54 \\
19 \\
53 \\
25 \\
55 \\
37\end{array}$ & $\begin{array}{l}\mathbf{M} \\
\mathbf{M} \\
\mathbf{M} \\
\mathbf{M} \\
\mathbf{M} \\
\mathbf{M} \\
\mathbf{F} \\
\mathbf{M} \\
\mathbf{M} \\
\mathbf{M} \\
\mathbf{M} \\
\mathbf{M} \\
\mathbf{M} \\
\mathbf{F} \\
\mathbf{M} \\
\mathbf{M} \\
\mathbf{M} \\
\mathbf{M}\end{array}$ & $\begin{array}{l}+++ \\
+++ \\
+++ \\
+++ \\
+++ \\
+++ \\
+++ \\
+++ \\
+++ \\
+++ \\
+++ \\
+++ \\
+++ \\
+++ \\
+++ \\
+++ \\
+++ \\
+++\end{array}$ & $\begin{array}{c}+++ \\
+++ \\
++ \\
+++ \\
+++ \\
+++ \\
+++ \\
+++ \\
+++ \\
+++ \\
+++ \\
+++ \\
+++ \\
+++ \\
+++ \\
+++ \\
+++ \\
+++\end{array}$ & $\begin{array}{c}\text { NR } \\
40 \\
\text { NR } \\
9 \\
8 \\
12 \\
6 \\
9 \\
11 \\
65 \\
50 \\
36 \\
28 \\
2 \\
8 \\
10 \\
24 \\
31\end{array}$ & $\begin{array}{l}\text { Good } \\
\text { Fair } \\
\text { Fair } \\
\text { Fair } \\
\text { Good } \\
\text { Good } \\
\text { Good } \\
\text { Good } \\
\text { Fair } \\
\text { Fair } \\
\text { Fair } \\
\text { Fair } \\
\text { Good } \\
\text { Good } \\
\text { Good } \\
\text { Good } \\
\text { Fair } \\
\text { Good }\end{array}$ & $\begin{array}{r}12 \\
38 \\
40 \\
48 \\
64 \\
66 \\
71 \\
72 \\
90 \\
95 \\
96 \\
102 \\
104 \\
108 \\
114 \\
119 \\
124 \\
130\end{array}$ & $\begin{array}{l}3 \cdot 2 \\
2.1 \\
2.4 \\
2 \cdot 1 \\
1.8 \\
2.6 \\
4 \cdot 7 \\
2.0 \\
3 \cdot 3 \\
1 \cdot 8 \\
2.0 \\
2.5 \\
3.4 \\
3.6 \\
2.4 \\
4.3 \\
2.6 \\
\text { NR }\end{array}$ & $\begin{array}{l}47 \\
37 \\
29 \\
56 \\
58 \\
49 \\
55 \\
50 \\
34 \\
69 \\
51 \\
44 \\
34 \\
67 \\
48 \\
40 \\
43 \\
51\end{array}$ \\
\hline
\end{tabular}

\begin{tabular}{|c|c|c|c|c|c|c|c|c|}
\hline \multicolumn{9}{|c|}{ Multivalve Series } \\
\hline $\begin{array}{l}42 \\
50 \\
55\end{array}$ & $\begin{array}{l}\mathbf{F} \\
\mathbf{M} \\
\mathbf{F}\end{array}$ & $\begin{array}{l}+ \\
+ \\
+\end{array}$ & $\begin{array}{c}++ \\
+++ \\
+\end{array}$ & $\begin{array}{r}0 \\
28 \\
16\end{array}$ & $\begin{array}{l}\text { Good } \\
\text { Good } \\
\text { Good }\end{array}$ & $\begin{array}{l}26 \\
50 \\
56\end{array}$ & $\begin{array}{l}2 \cdot 7 \\
2 \cdot 3 \\
2 \cdot 5\end{array}$ & $\begin{array}{l}56 \\
31 \\
32\end{array}$ \\
\hline 51 & $\mathbf{M}$ & ++ & ++ & 0 & Fair & 32 & $2 \cdot 2$ & 37 \\
\hline
\end{tabular}

1 At time of operation. + mild; ++ moderate; +++ severe; NR = not recorded; AR = aortic regurgitation.

second operation. A further five patients have gone to surgery for homograft replacement on clinical criteria alone without cardiac catheterization. One of these had had rather an indifferent first operation, but in the other four instances the surgeon had been well pleased. At the second operation, four had tight restenosis with gross calcification; the fifth was judged to have only relatively mild valve disease but appeared to have a cardiomyopathy. The 13 homograft valve replacements were performed at intervals of 21 to 67 months after the original surgery, and all these patients are still alive.

There remain four of the 38 survivors followed up in whom direct evidence as to the state of the valve, either by cardiac catheterization or repeat surgery, was not obtained. Catheterization was withheld in this small group for other than medical reasons, and they were assessed clinically only. Two were doing well, better than average for the group as a whole, but were followed up only 25 and 34 months after débridement; the third showed some improvement but was moderately limited, and the fourth had sustained a massive myocardial infarct since surgery.

In summary, then, of the 38 patients with isolated valve disease in whom follow-up was undertaken, only one appears to have maintained a good result after a substantial post-operative interval ; four others are apparently satisfactory, but the post-operative interval in each case has been no longer than three years. One patient has aortic regurgitation. All the other 32 patients have significant restenosis, often severe. 


\section{MULTIVALVE GROUP}

This comprised 15 patients with mitral as well as aortic valve disease (and sometimes also tricuspid valve involvement). They are only briefly discussed since aortic valve disease and its effects are influenced by coincident mitral disease. As in the patients with isolated aortic valve disease, they were assessed mainly on clinical, electrocardiographic, and radiological evidence before surgery. At operation, 13 were found to have severe aortic stenosis, but, in contrast to the single valve group, calcification was heavy in only two valves. One of the 15 required Teflon cusp insertion; another three died on the operating table. Four more have died since discharge (Table IV). Four of the seven survivors of standard débridement have had follow-up cardiac catheterization (Table V), and three of these have been reoperated upon. Although the seven survivors as a group gave evidence of restenosis of the aortic valve, only two appeared to have severe stenosis or calcification. In general, the sculptured valve appears to have deteriorated less in this than in the single valve group. In the group of 15 as a whole, those with the heaviest valve calcification did worst, as regards both mortality and restenosis.

\section{DISCUSSION}

This series has a longer average follow-up period than any yet reported. The pre-operative data and operative findings confirm that the majority of patients were in fact suffering from severe calcific aortic stenosis. Débridement-valvotomy was performed as the operation of choice for aortic stenosis in this unit for most of the period between 1959 and 1963. In August 1962 the first aortic homograft replacement was performed, and this gradually replaced débridement, which has been virtually discontinued since early 1964 . Apart from this dichotomy in the last year or so under review, the débridement series represents an unselected group of adults with severe aortic stenosis.

Our patients have had a high mortality rate, both hospital and late. The hospital mortality was $21 \%$, and late mortality $10 \%$ in the univalve series; the respective figures for the multivalve series were $20 \%$ and $27 \%$. The total of 26 deaths in 76 patients represents a combined early and late mortality of $34 \%$. This includes four Teflon cusp fatalities, who are included since the necessity for cusp replacement was an expression of a failed débridement. Hospital mortality rates in other large series vary considerably; with Mulder, Kattus, Fonkalsrud, and Longmire (1963) hospital mortality was $14 \%$, with McGoon, Ellis, and Kirklin (1965) 14\%, Cronin, Reid, Scott, and Dobell (1963) 25\%, Scannell, Shaw, Burke, Austen, and Saurbrey (1963) $27 \%$, and Baker and Somerville (1964) $31 \%$. Considerably better results were achieved by Morrow, Austen, and Braunwald (1963) with an $8 \%$ hospital mortality, by Hufnagel and Conrad (1962) 6\%, and Hancock, Hultgren and Shumway (1965) 3\%.

Late mortality figures in our own and other series are less easily compared, since the followup intervals vary. Thus McGoon et al. (1965) had a late mortality of $23 \%$, with an average follow-up period of approximately three years, Scannell et al. (1963) 9\% over two to five years, Hancock et al. (1965) $10 \%$ over an average of 28 months, and Morrow et al. (1963) $8 \%$ and Hufnagel and Conrad (1962) $12 \%$ over one year We find our own hospital and late mortality rates unacceptably high when compared with our figures for homograft replacement for adult aortic stenosis, namely $7 \%$ hospital mortality and $5 \%$ late mortality after six to 48 months in 107 patients (Barratt-Boyes, 1967).

The main reason, however, for our rejection of débridement lies in our follow-up catheter and operative data. In the single valve group, only one patient can be claimed as a proven good longterm result. Four others seem acceptable at present, but their reviews were carried out after relatively short post-operative intervals and, by analogy with the rest of the series, they might be expected to undergo further significant deterioration in the near future. On the other hand, many of our patients have quite clearly had bad results, whether assessed clinically or haemodynamically. An average peak systolic gradient at catheterization of $74 \mathrm{~mm} . \mathrm{Hg}$ and the presence of radiologically visible calcium in $97 \%$ of valves (heavy in the majority) at follow-up cannot be accepted as a satisfactory result of an operation intended to produce a mobile calcium-free valve. Of 13 patients who have been reoperated on, 12 displayed tight restenosis of their valves, all but one of which were grossly calcified. Some valves looked as if no previous surgery had been performed.

It has been suggested (McGoon et al., 1965) that the operation may still have a place in cases where valve calcification is not heavy. Our series does not support this contention. Our only case of long-term aortic regurgitation was in a very lightly calcified valve ; all but one of the remainder with initial light or moderate calcification had transaortic gradients of more than $40 \mathrm{~mm}$. $\mathrm{Hg}$ at 
follow-up (Table V). Most of those with heavy calcification did undergo severe restenosis, but the best result of all also came from this group.

Our results make us unable to support the claim of Hancock et al. (1965) that the operation can achieve a satisfactory long-term result in as many as $25 \%$ of cases. Similarly encouraging reports were made by Morrow et al. (1963) and Scannell et al. (1963) after short follow-ups, although they admitted that later results might be less favourable. Baird, Lipton, Labrosse, Wigle, Bigelow, Heimbecker, and Key (1965) were more guarded and felt that the procedure should probably be restricted to those with only minimal or moderate calcification in whom débridement will be complete. As early as 1963, Mulder et al., among others, stated that débridement cannot be relied upon to provide sustained relief of valvar stenosis. Yet McGoon et al. (1965) concluded that the method could not yet be excluded and might continue to enjoy limited application, particularly in certain selected cases where the restoration of excellent valve mobility could be anticipated. In our series, however, many of the best immediate operative results were in patients who subsequently displayed high transvalvar gradients at follow-up.

These conflicting opinions illustrate that lingering controversy about débridement still exists notwithstanding its widespread displacement by aortic valve replacement procedures. Our observations in the catheter room or operating theatre convince us that in aortic stenosis among adults significant restenosis will almost invariably follow valvar débridement, no matter how thorough or immediately successful. While still short by usual criteria, our mean follow-up interval has been longer than in other series, and we expect that the incidence of good late results in these series will progressively fall as the average post-operative period lengthens. We feel that débridementvalvotomy should no longer be considered as a suitable treatment for calcific aortic stenosis.

\section{REFERENCES}

Bahnson, H. T., Spencer, F. C., Busse, E. F. G., and Davis, F. W. (1960). Cusp replacement and coronary artery perfusion in open operations on the aortic valve. Ann. Surg., 152, 494.

Baird, R. J., Lipton, I. H., Labrosse, C. J., Wigle, E. D., Bigelow, W. G., Heimbecker, R. O., and Key, J. A. (1965). An evaluation of the late results of aortic valve repair. J. thorac. cardiovasc. Surg., 49, 562.

Baker, C., and Somerville, J. (1964). Results of surgical treatment of aortic stenosis. Brit. med. J., 1, 197.

Barratt-Boyes, B. G. (1967). Homograft replacement for aortic valve disease. Mod. Conc. cardiovasc. Dis., 36, 1.

Cronin, R. F. P., Reid, E. A. S., Scott, H. J., and Dobell, A. R. C. (1963). A clinical survey of 20 patients submitted to aortic valvuloplasty. Brit. Heart J., 25, 663.

Hancock, E. W., Hultgren, H. N., and Shumway, N. E. (1965). Clinical and hemodynamic results of debridement-valvotomy for calcific aortic stenosis. Surg. Gynec. Obstet., 120, 770.

Hufnagel, C. A., and Conrad, P. W. (1962). Calcific aortic stenosis. New Engl. J. Med., 266, 72

McGoon, D. C., Ellis, F. H. Jr., and Kirklin, J. W. (1965). Late results of operation for acquired aortic valvular disease. Circulation, 31, Suppl. 1, p. 108.

Morrow, A. G., Austen, W. G., and Braunwald, E. (1963). The surgical treatment of calcific aortic stenosis: operative methods and the results of the pre- and postoperative hemodynamic assessments. Ann. Surg., 158, 936.

Mulder, D. G., Kattus, A. A., Fonkalsrud, E. W., and Longmire, W. P. (1963). The surgical treatment of acquired aortic stenosis. J. thorac. cardiovasc. Surg., 46, 468.

Scannell, J. G., Shaw, R. S., Burke, J. F., Austen, W. G., and Saurbrey, J. S. (1963). Operative treatment of aortic stenosis in the adult. Circulation, 27, 772. 